\title{
Evaluating the cost-effectiveness of insulin detemir versus neutral protamine Hagedorn insulin in patients with type I or type 2 diabetes in the UK using a short-term modeling approach
}

This article was published in the following Dove Press journal: Diabetes, Metabolic Syndrome and Obesity:Targets and Therapy

\author{
Richard F Pollock' \\ Barrie Chubb² \\ William J Valentine' \\ Simon Heller ${ }^{3}$ \\ 'Health Economics and Outcomes \\ Research, Ossian Health Economics \\ and Communications $\mathrm{GmbH}$, \\ Basel, Switzerland; ${ }^{2}$ EU-HEOR, \\ Novo Nordisk Limited, Gatwick, \\ UK; ${ }^{3}$ Department of Oncology \\ \& Metabolism, The University of \\ Sheffield, Sheffield, UK
}

Background: To estimate the short-term cost-effectiveness of insulin detemir (IDet) versus neutral protamine Hagedorn (NPH) insulin based on the incidence of non-severe hypoglycemia and changes in body weight in subjects with type 1 diabetes (T1D) or type 2 diabetes (T2D) in the UK.

Methods: A model was developed to evaluate cost-effectiveness based on non-severe hypoglycemia, body mass index, and pharmacy costs over 1 year. Published rates of non-severe hypoglycemia were employed in the T1D and T2D analyses, while reduced weight gain with IDet was modeled in the T2D analysis only. Effectiveness was calculated in terms of qualityadjusted life expectancy using published utility scores. Pharmacy costs were captured using published prices and defined daily doses. Costs were expressed in 2016 pounds sterling (GBP). Sensitivity analyses were performed (including probabilistic sensitivity analysis).

Results: In T1D, IDet was associated with fewer non-severe hypoglycemic events than NPH insulin (126.7 versus 150.8 events per person-year), leading to an improvement of 0.099 qualityadjusted life years (QALYs). Costs with IDet were GBP 60 higher, yielding an incremental cost-effectiveness ratio (ICER) of GBP 610 per QALY gained. In T2D, mean non-severe hypoglycemic event rates and body weight were lower with IDet than NPH insulin, leading to a total incremental utility of 0.120 , accompanied by an annual cost increase of GBP 171, yielding an ICER of GBP 1,422 per QALY gained for IDet versus NPH insulin.

Conclusion: Short-term health economic evaluation showed IDet to be a cost-effective alternative to NPH insulin in the UK due to lower rates of non-severe hypoglycemia (T1D and T2D) and reduced weight gain (T2D only).

Keywords: cost-benefit analysis, insulin, diabetes mellitus type 1, diabetes mellitus type 2, hypoglycemia

\section{Plain language summary}

The present study evaluated the cost-effectiveness of neutral protamine Hagedorn (NPH) insulin relative to insulin detemir ([IDet] Levemir ${ }^{\mathbb{R}}$; Novo Nordisk A/S, Bagsværd, Denmark) from the perspective of the UK National Health Service (NHS). Although the two insulins have slightly different durations of action, both are widely used as the "basal" component of a patient's insulin regimen, providing glycemic control over the course of the day (as opposed to "bolus" insulin, which is administered at mealtimes in patients with type 1 diabetes or more advanced type 2 diabetes). Numerous clinical studies have demonstrated that IDet results in less day-to-day variation in blood glucose levels, fewer episodes of hypoglycemia (very low blood glucose), and less weight gain relative to NPH insulin. In the UK, however, NPH insulin is currently $46 \%$
Correspondence: Richard F Pollock

Ossian Health Economics and

Communications $\mathrm{GmbH}$, Bäumleingasse

20, 405I Basel, Switzerland

Tel +4I 6I 27I 62I4

Email pollock@ossianconsulting.com 
cheaper than IDet on a per-unit basis ( $£ 0.015$ versus $£ 0.028$ when each insulin dose is purchased in a pen cartridge for injection). As NHS England faces increasing budget constraints, balancing the additional cost of IDet with the clinical benefits it provides is an important aspect of ensuring good value for money for the NHS. Here, we used a short-term (1 year) computer model to establish if differences between IDet and NPH insulin in terms of insulin dosing, hypoglycemia, and, in type 2 diabetes, body mass index, were worth the additional cost to the NHS.

\section{Introduction}

Long-term studies such as the Diabetes Control and Complications Trial (DCCT) in type 1 diabetes have shown that improved glycemic control leads to improved longterm outcomes. ${ }^{1}$ Long-term studies in type 2 diabetes, such as the United Kingdom Prospective Diabetes Study (UKPDS), have similarly shown unequivocal benefits of improved glycemic control in terms of microvascular and macrovascular benefits. ${ }^{2}$ Epidemiological studies have also demonstrated reduced incidence of macrovascular complications with improved glycemic control. ${ }^{3}$ Lower blood glucose levels are, however, accompanied by an increased risk of hypoglycemia. In the DCCT, patients in the intensive treatment group were exposed to a threefold higher rate of severe hypoglycemia (61.2 events per 100 patient years versus 18.7 events per 100 patient years in the conventional treatment group). ${ }^{4}$ The severity of hypoglycemic episodes ranges from relatively mild, which can be remedied by eating fast-acting carbohydrates, through to severe events that can result in seizure, coma, and occasionally death. Real-world data from the UK collected from 466 patients with type 1 diabetes over a period of 4 weeks (7-day recall period) indicated an average non-severe hypoglycemic event rate in individuals with type 1 diabetes of 126.7 events per patient per year, equivalent to experiencing an event every 3 days. $^{5}$ While hypoglycemia is less frequent in patients with type 2 diabetes than patients with type 1 diabetes, hypoglycemia becomes progressively more frequent as the disease progresses, with the same study reporting a rate of 41.5 events per patient per year in insulin-using patients with type 2 diabetes. ${ }^{5,6}$ Evidence from a variety of sources has also shown that hypoglycemic events reduce quality of life and workplace productivity, ${ }^{7-14}$ and increase health care resource utilization. ${ }^{11}$

Long-acting insulin analogues such as IDet can reduce the rate of non-severe hypoglycemia in individuals with type 1 or type 2 diabetes relative to NPH insulin. Indeed, several trials have provided evidence that treatment with IDet results in predictable glycemic control with less day-to-day variation, fewer hypoglycemic episodes, and decreased weight gain in comparison with NPH insulin. ${ }^{15-21}$ The clinical benefit of reduced non-severe hypoglycemia comes at an additional cost, however, with drug costs associated with IDet being higher than those of NPH insulin in most countries.

The present modeling analysis is therefore designed to provide an insight into whether the additional cost of IDet is justified in terms of the clinical benefit it provides in patients with type 1 or type 2 diabetes.

\section{Methods}

A cost-effectiveness model was developed in Microsoft Excel 2010 to evaluate the cost-effectiveness of IDet relative to NPH insulin in patients with type 1 or type 2 diabetes. The model adopted the perspective of a UK health care payer (the National Health Service), and the base-case analysis was conducted over a 1-year time horizon, negating the need for discounting of cost or effectiveness outcomes. The 1-year time horizon was selected on the grounds that NPH insulin and IDet both have the same mechanism of action, and any differences in the long-term incidence of diabetes complications could be mitigated by adjusting the respective insulin doses.

The model captured insulin, needle and self-monitoring of blood glucose (SMBG) costs, costs of other antidiabetes therapies, and costs associated with non-severe hypoglycemic events. All costs were expressed in 2016 pounds sterling (GBP). Concomitant medication costs such as antihypertensive and lipid lowering agents were assumed to be equivalent in both arms and excluded from the analysis. Differences in glycemic control and other risk factors such as blood pressure were also excluded on the grounds that glycemic control can be achieved by simply titrating up the dose of insulin and high blood pressure can be controlled using relatively low-cost antihypertensives. However, differences in body mass index (BMI) were captured in the analysis of type 2 diabetes to evaluate the effect on healthrelated quality of life.

\section{Hypoglycemia rates}

Hypoglycemia rates in patients with type 1 or type 2 diabetes using IDet were taken from a 2013 UK-specific study on self-reported rates of hypoglycemia in 1,038 adult patients with type $1(n=466)$ or type $2(n=572)$ diabetes. ${ }^{5}$ In the type 1 base-case analysis, the non-severe hypoglycemic event rate for patients receiving NPH insulin was calculated by applying a rate ratio of 1.19 (the reciprocal of 0.84 ) to the 
UK base rate of 126.7 events per patient year with IDet, yielding a deterministic rate estimate with NPH insulin of 150.8 events per patient year. The rate ratio was taken from a meta-analysis of six clinical trials of IDet versus NPH insulin comprising over 2,109 subjects with type 1 diabetes as part of a health technology assessment by the Canadian Agency for Drugs and Technology in Health (CADTH) published in $2008 .^{22}$ The mean reciprocal rate ratio of 1.19 was used in the base-case analysis and the corresponding 95\% CI of 1.03-1.35 was used both for probabilistic sensitivity analysis (PSA) and to calculate the non-severe hypoglycemic event rate on NPH insulin for "pessimistic" and "optimistic" scenarios, respectively.

The type 2 base-case analysis utilized an overall hypoglycemia relative rate from the same CADTH meta-analysis as used in the analysis of type 1 diabetes, with a mean rate ratio of 0.59 for IDet relative to NPH insulin. The reciprocal rate ratio of 1.69 (95\% CI 1.39-2.08) was applied to the IDet base rate of 41.5 events per patient year from the UK self-report study, to give a deterministic rate estimate of 70.34 events per patient year with NPH insulin.

Severe hypoglycemic events were not included in either the type 1 or type 2 analyses as the same CADTH metaanalysis reported a non-significant difference between treatments, with a rate ratio for severe hypoglycemia of 0.95 (95\% CI $0.65-1.38)$ in patients on IDet relative to NPH insulin. $^{22}$

\section{Insulin dosing and concomitant medications}

Insulin doses in the analysis of patients with type 1 diabetes were derived from a population of 437 adults enrolled in the Dose Adjustment For Normal Eating (DAFNE) structured education program. ${ }^{23}$ Specifically, mean basal insulin dosing was modeled at 24.35 IU per day, while mean bolus insulin dosing was assumed to be 27.88 IU per day. In the type 1 base-case analysis, dosing of IDet and NPH insulin was assumed to be equivalent. In the type 2 (basal-only) analysis, insulin doses were modeled in line with data from the PREDICTIVE study, assuming doses of $0.47 \mathrm{IU} / \mathrm{kg} /$ day for NPH insulin and $0.59 \mathrm{IU} / \mathrm{kg} /$ day for IDet and based on a mean body weight of $76 \mathrm{~kg}$ in line with the baseline weight of the UKPDS insulin starter group. ${ }^{2,24}$ In addition to insulin, patients with type 2 diabetes were assumed to take 2,000 $\mathrm{mg}$ of metformin a day and $60 \mathrm{mg}$ of gliclazide in line with the World Health Organization defined daily doses of metformin and sulfonylurea, respectively.

\section{Self-monitoring of blood glucose}

Patients with type 1 diabetes were assumed to perform SMBG tests four times daily in line with 2015 guidance from the National Institute for Health and Care Excellence, which specifically recommends "testing at least 4 times a day, including before each meal and before bed" in patients with type 1 diabetes without any specific need to test more frequently. ${ }^{25}$ This is likely to be a conservative estimate as many patients meet the criteria for more frequent testing, such as involvement in sports or high-risk activities, impaired awareness of hypoglycemia, illness, pregnancy, or failure to achieve the desired glycated hemoglobin (HbA1c) target. Patients with type 2 diabetes were assumed to perform SMBG three times a day on 2 days a week (an average of 0.86 tests per day) in line with the DiGEM trial, which investigated the effect of different SMBG strategies on glycemic control in patients with type 2 diabetes. ${ }^{26,27}$

\section{Quality of life}

In the base-case analysis, a quality of life disutility of -0.004 was associated with each non-severe hypoglycemic event, based on a 2013 study by Evans et al. ${ }^{28}$ The type 2 diabetes analysis also associated a disutility with increased BMI derived from the CADTH meta-analysis. The difference in body weight reported in the meta-analysis $(0.96 \mathrm{~kg}$ higher with NPH insulin than with IDet) was converted to a mean difference in BMI using a mean height of $1.72 \mathrm{~m}$, and a disutility of -0.0061 per additional BMI unit was applied based on the time trade-off model coefficient for each BMI unit over $25 \mathrm{~kg} / \mathrm{m}^{2}$ reported by Bagust and Beale. ${ }^{29,30}$ Baseline quality of life with no complications in patients with type 1 or type 2 diabetes was taken to be 0.81 based on a 2011 meta-analysis by Lung et al. ${ }^{31}$

\section{Unit costs}

Costs of insulin (NPH, IDet, and bolus insulin in the type 1 analysis), metformin, and sulfonylurea were taken from the British National Formulary (Table 1). Costs of needles, SMBG test strips, and lancets were taken from the NHS Business Services Authority. The cost of hypoglycemic events was taken from a recent analysis of the cost of non-severe hypoglycemia in 10 European countries including the UK. ${ }^{32}$ The analysis was based on data from the Hypoglycaemia in Insulin Treated Patients (HIT) study, ${ }^{5}$ and captured costs of additional SMBG test strip use and contact with health care professionals (either by telephone consultation, or visit to a nurse or primary care physician) in a country-specific proportion of patients with type 1 or type 2 diabetes. 
Table I Unit costs in the base-case analysis

\begin{tabular}{|c|c|c|c|}
\hline & Cost & Cost basis & Reference \\
\hline NPH insulin (GBP per IU) & 0.015 & Insulatard Penfill ${ }^{\circledR}$ cartridge $100 \mathrm{IU} / \mathrm{mL}, 5 \times 3 \mathrm{~mL}$ & BNF, September 2016 \\
\hline Insulin detemir (GBP per IU) & 0.028 & Levemir $^{\circledR}$ Penfill ${ }^{\circledR}$ cartridge $100 \mathrm{IU} / \mathrm{mL}, 5 \times 3 \mathrm{~mL}$ & BNF, September 2016 \\
\hline Bolus insulin (GBP per IU) & 0.019 & NovoRapid ${ }^{\circledR}$ Penfill ${ }^{\circledR}$ cartridge $100 \mathrm{IU} / \mathrm{mL}, 5 \times 3 \mathrm{~mL}$ & BNF, September 2016 \\
\hline Metformin (GBP per gram) & 0.027 & Metformin tablets, $850 \mathrm{mg}$, 56 tablet pack & BNF, September 2016 \\
\hline Gliclazide (GBP per milligram) & 0.003 & Gliclazide tablets, 40 mg, 28 tablet pack & BNF, September 2016 \\
\hline Needles (GBP per needle) & 0.03 & BD Micro-Fine $0.3 \mathrm{~mm} / 30$ gauge, 200 needle pack & NHS BSA, September 2016 \\
\hline SMBG test strip (GBP per strip) & 0.319 & Accu-Chek Aviva, 50 strip pack & NHS BSA, September 2016 \\
\hline Lancet (GBP per lancet) & 0.049 & FastClix (Roche Diabetes Care Ltd), 204 lancet pack & NHS BSA, September 2016 \\
\hline Hypoglycemic event TID (GBP) & 2.193 & Additional strips and HCP contacts & 33 \\
\hline Hypoglycemic event T2D (GBP) & 3.066 & Additional strips and HCP contacts & 33 \\
\hline
\end{tabular}

Abbreviations: NPH, neutral protamine Hagedorn; BD, Becton Dickinson; GBP, 2016 pounds sterling; HCP, health care professional; IU, international units; NHS BSA, National Health Service Business Services Authority; SMBG, self-monitoring of blood glucose; BNF, British National Formulary; TID, type I diabetes; T2D, type 2 diabetes.

\section{Sensitivity analysis}

A series of sensitivity analyses were conducted to establish the magnitude by which model outcomes changed in response to changes in individual input parameters. In the type 2 diabetes analyses, insulin doses were changed to match those reported by Eliasson et al ( $29.9 \mathrm{IU} /$ day with NPH insulin and $42.1 \mathrm{IU} /$ day with IDet). ${ }^{33}$ In both type 1 and type 2 diabetes analyses, the hypoglycemia rate ratio was set at 0.78 (from Bartley et al) in the type 1 diabetes analysis and 0.7 (from Tajima et al) in the type 2 diabetes analysis, compared to 0.84 and 0.59 in the respective base-case analyses. ${ }^{21,34}$ The base rates of hypoglycemia in the IDet arm were also modified to match those reported by the UK Hypoglycemia Study Group (UKHSG; 35.5 events per patient per year for type 1 diabetes and 4.08 events per patient per year for type 2 diabetes). ${ }^{35}$ Further analyses were conducted in which the quality of life disutility associated with each hypoglycemic event was changed to values from Currie et al ${ }^{10}(-0.0035)$, Levy et al $(-0.0033, \mathrm{SD}=0.0004),{ }^{7}$ and using a diminishing marginal hypoglycemia utility model published by Lauridsen et al. ${ }^{36}$ Finally, the disutility associated with increased BMI was abolished in an analysis around the type 2 diabetes base case.

\section{Results}

Using non-severe hypoglycemia rate ratios and body weight differences from a recent CADTH meta-analysis, the present analysis showed IDet to be cost-effective relative to NPH insulin in patients with either type 1 or type 2 diabetes in the UK setting over a 1-year time horizon.

In patients with type 1 diabetes, the deterministic analysis showed an increase in costs of GBP 60 with IDet relative to NPH insulin over a 1-year time horizon (GBP 1,301 relative to GBP 1,241). The reduced rate of hypoglycemia resulted in a quality-adjusted life expectancy gain of 0.099 qualityadjusted life years (QALYs), resulting in an incremental cost-effectiveness ratio (ICER) of GBP 610 per QALY gained (Table 2). The equivalent analysis in patients with type 2 diabetes showed a cost increase of GBP 171 with IDet relative to NPH insulin over a 1-year time horizon (GBP 798 relative to GBP 627). The reduced rate of hypoglycemia with IDet combined with the smaller increase in BMI resulted in a gain of 0.120 QALYs, resulting in an ICER of GBP 1,422 per QALY gained.

PSA yielded similar outcomes to the deterministic base-case analyses with incremental quality-adjusted life expectancy of 0.101 QALYs (standard deviation [SD] 0.038 QALYs) and incremental costs of GBP 59 (SD GBP 45) in the type 1 analysis, resulting in an ICER of GBP 587 per QALY gained. In the type 2 diabetes PSA, incremental costs were GBP 173 (SD GBP 202) and incremental quality-adjusted life expectancy was 0.123 QALYs (SD 0.028 QALYs), resulting in an ICER of GBP 1,408 per QALY gained. Results of the 10,000 model iterations were plotted on a scatterplot, and cost-effectiveness acceptability curves were generated over a range of willingness-to-pay (WTP) thresholds (Figures 1-4). At a WTP threshold of GBP 10,000 per QALY gained, there was a $99.9 \%$ likelihood that detemir would be cost-effective relative to NPH insulin in patients with type 1 diabetes. In patients with type 2 diabetes, there was a $100 \%$ likelihood of cost-effectiveness at the same WTP threshold.

One-way sensitivity analysis results showed the model to be sensitive to assumptions around the hypoglycemia base rate and rate ratios, and the use of a per-event utility model versus a diminishing marginal utility (DMU) model (Table 3). Notably, setting the hypoglycemia rate ratio to 0.78 resulted in an analysis in which IDet was relatively more effective than NPH insulin in type 1 diabetes, with an incremental quality-adjusted life expectancy of 0.147 QALYs and additional costs of GBP 35 with IDet, resulting in an ICER of GBP 238 per QALY gained. In the type 2 
Table 2 Cost-effectiveness of insulin detemir versus NPH insulin in the UK

\begin{tabular}{llllllll}
\hline & $\begin{array}{l}\text { NPH insulin } \\
\text { cost (GBP) }\end{array}$ & $\begin{array}{l}\text { Insulin detemir } \\
\text { cost (GBP) }\end{array}$ & $\begin{array}{l}\text { Incremental } \\
\text { cost (GBP) }\end{array}$ & $\begin{array}{l}\text { NPH } \\
\text { effectiveness } \\
\text { (QALYs) }\end{array}$ & $\begin{array}{l}\text { Insulin detemir } \\
\text { effectiveness } \\
\text { (QALYs) }\end{array}$ & $\begin{array}{l}\text { Incremental } \\
\text { effectiveness } \\
\text { (QALYs) }\end{array}$ & $\begin{array}{l}\text { ICER (GBP per } \\
\text { QALY gained) }\end{array}$ \\
\hline Type I diabetes & $\mathrm{I}, 24 \mathrm{I}$ & $\mathrm{I}, 30 \mathrm{I}$ & +60 & 0.192 & 0.291 & 0.099 & 610 \\
Type 2 diabetes & 627 & 798 & +171 & 0.520 & 0.640 & 0.120 & 1,422 \\
\hline
\end{tabular}

Abbreviations: GBP, 2016 pounds sterling; NPH, neutral protamine Hagedorn; QALY, quality-adjusted life year; ICER, incremental cost-effectiveness ratio.

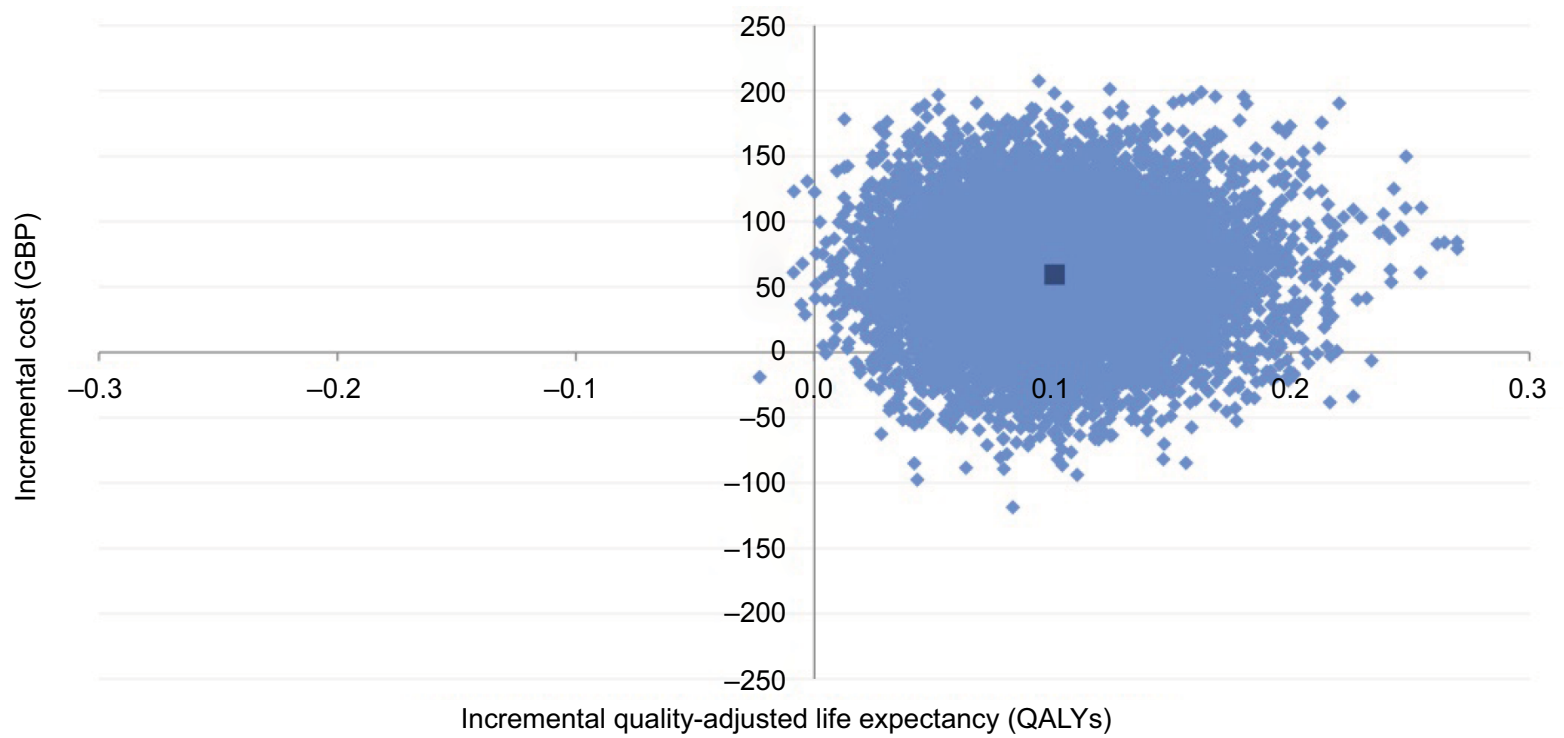

Figure I Cost-effectiveness scatter plot for insulin detemir relative to NPH insulin in patients with type I diabetes.

Abbreviations: NPH, neutral protamine Hagedorn; QALY, quality-adjusted life year; GBP, 2016 pounds sterling.

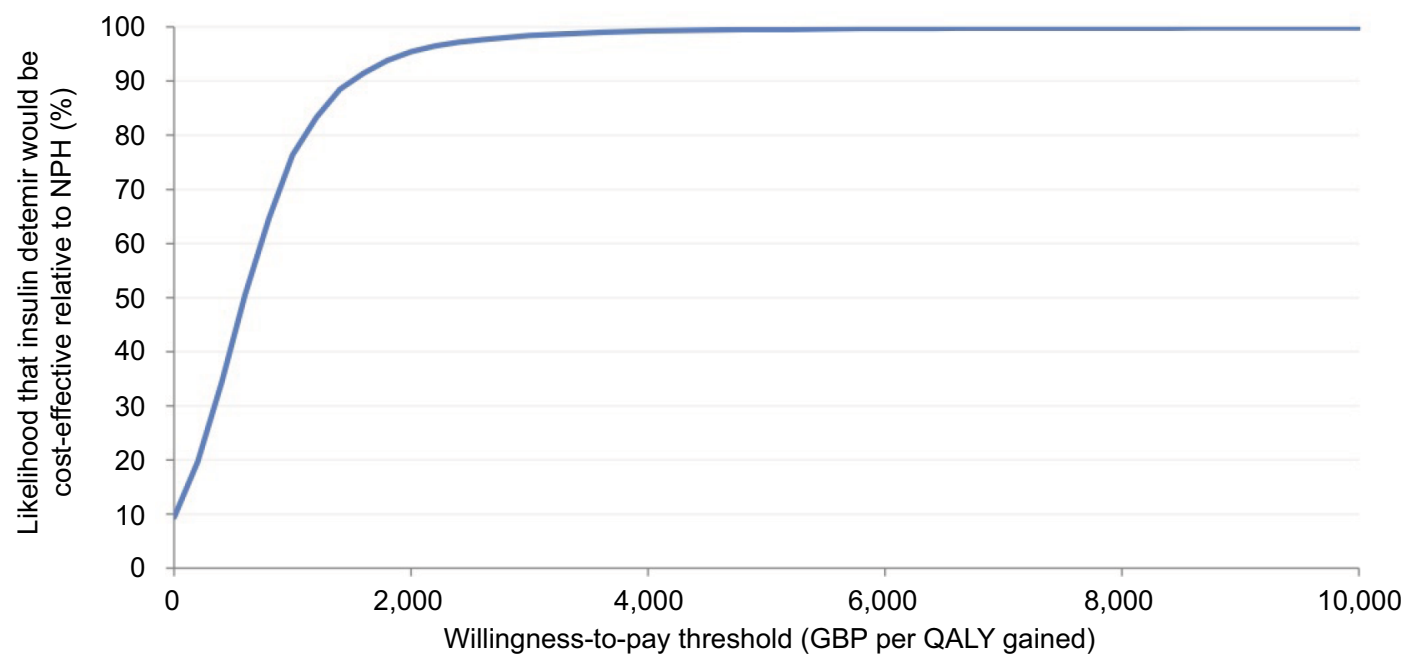

Figure 2 Cost-effectiveness acceptability curve for insulin detemir relative to NPH insulin in patients with type I diabetes.

Abbreviations: NPH, neutral protamine Hagedorn; QALY, quality-adjusted life year; GBP, 2016 pounds sterling.

diabetes analysis, reducing the hypoglycemia rate difference to that reported by Tajima et al increased the ICER to GBP 2,735 per QALY gained. ${ }^{34}$ Changing the hypoglycemia disutilities to values from studies other than Evans et al on a per-event basis resulted in relatively small changes in the ICER, while switching to use the Lauridsen et al's diminishing hypoglycemia utility model increased the ICER to GBP 13,578 per QALY gained and GBP 14,533 per QALY 


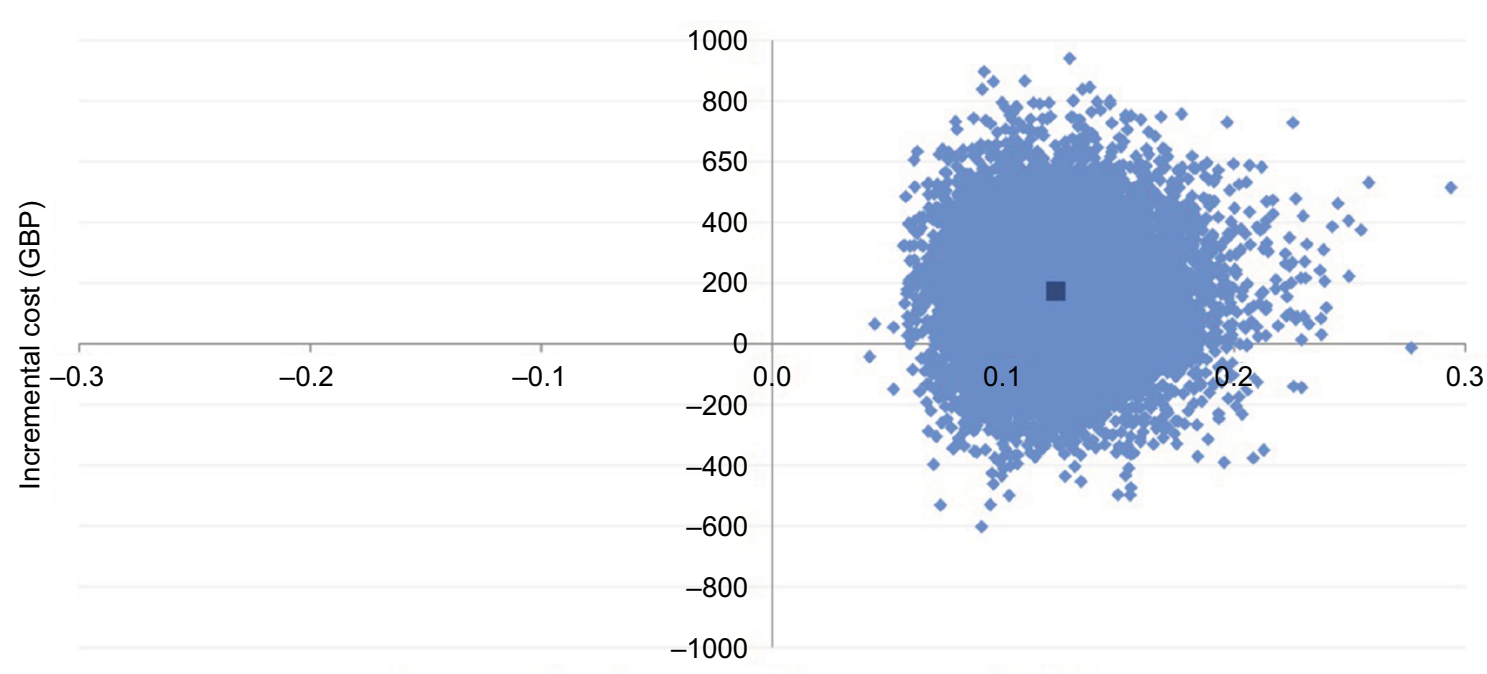

Incremental quality-adjusted life expectancy (QALYs)

Figure 3 Cost-effectiveness scatter plot for insulin detemir relative to NPH insulin in patients with type 2 diabetes.

Abbreviations: NPH, neutral protamine Hagedorn; QALY, quality-adjusted life year; GBP, 2016 pounds sterling.

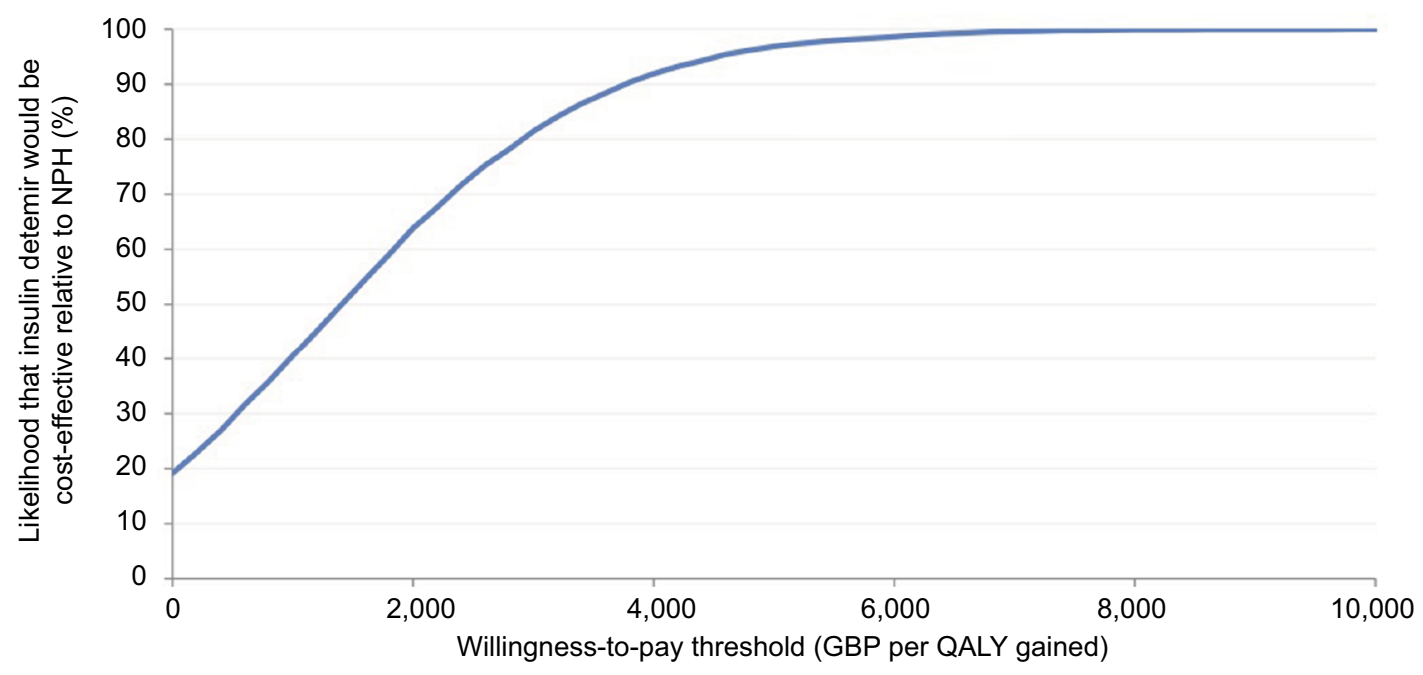

Figure 4 Cost-effectiveness acceptability curve for insulin detemir relative to NPH insulin in patients with type 2 diabetes. Abbreviations: NPH, neutral protamine Hagedorn; QALY, quality-adjusted life year; GBP, 2016 pounds sterling.

gained in the analyses of type 1 and type 2 diabetes, respectively. ${ }^{28,36}$ Changing the insulin dose assumptions in the type 2 diabetes analysis based on Eliasson et al resulted in an ICER of GBP 1,459 per QALY gained, a slight increase over the base-case analysis. ${ }^{33}$ Finally, by using rates of hypoglycemia from the UKHSG substantially increased the ICERs from GBP 610 per QALY gained to GBP 3,550 per QALY gained in the type 1 analysis, and from GBP 1,422 per QALY gained to GBP 18,429 per QALY gained in the type 2 analysis.

\section{Discussion}

The modeling approach used in the present analyses demonstrated that IDet would be considered cost-effective relative to NPH insulin in patients with type 1 or type 2 diabetes in the
UK. The analysis only captured differences in costs associated with antidiabetic medications and non-severe hypoglycemic events, and did not take into consideration other differences such as severe hypoglycemia and glycemic control. Needles and SMBG were also captured in the analysis, but were not a driver of differences between IDet and NPH insulin. The modeling approach is likely to be conservative with regard to the incremental cost-effectiveness of IDet relative to NPH insulin. For instance, randomized controlled trials and metaanalyses have demonstrated improved glycemic control with IDet relative to NPH, including a 2011 systematic review and meta-analysis of 10 randomized controlled trials including 3,825 patients, which showed a weighted mean $\mathrm{HbA} 1 \mathrm{c}$ difference of $-0.073 \%$ ( $p=0.021)$ with IDet relative to NPH and 
Table 3 One-way sensitivity analysis results

\begin{tabular}{|c|c|c|c|c|c|c|c|}
\hline & $\begin{array}{l}\text { NPH insulin } \\
\text { cost (GBP) }\end{array}$ & $\begin{array}{l}\text { Insulin } \\
\text { detemir } \\
\text { cost (GBP) }\end{array}$ & $\begin{array}{l}\text { Incremental } \\
\text { cost (GBP) }\end{array}$ & $\begin{array}{l}\text { NPH } \\
\text { effectiveness } \\
\text { (QALYs) }\end{array}$ & $\begin{array}{l}\text { Insulin } \\
\text { detemir } \\
\text { effectiveness } \\
\text { (QALYs) }\end{array}$ & $\begin{array}{l}\text { Incremental } \\
\text { effectiveness } \\
\text { (QALYs) }\end{array}$ & $\begin{array}{l}\text { ICER (GBP } \\
\text { per QALY } \\
\text { gained) }\end{array}$ \\
\hline \multicolumn{8}{|l|}{ Type I diabetes } \\
\hline Base case & $|, 24|$ & $\mathrm{I}, 30 \mathrm{I}$ & +60 & 0.192 & 0.291 & +0.099 & 610 \\
\hline Hypoglycemia rate ratio of $0.78^{21}$ & 1,266 & $\mathrm{I}, 30 \mathrm{I}$ & +35 & 0.144 & 0.291 & +0.147 & 238 \\
\hline Levy et al hypoglycemia disutility ${ }^{7}$ & $\mathrm{I}, 24 \mathrm{I}$ & $\mathrm{I}, 30 \mathrm{I}$ & +60 & 0.312 & 0.392 & +0.080 & 757 \\
\hline Currie et al hypoglycemia disutility ${ }^{10}$ & $|, 24|$ & $\mathrm{I}, 30 \mathrm{I}$ & +60 & 0.282 & 0.367 & +0.084 & 714 \\
\hline Diminishing hypoglycemia utility & $|, 24|$ & $\mathrm{I}, 30 \mathrm{I}$ & +60 & 0.733 & 0.737 & +0.004 & 13,578 \\
\hline UKHSG base hypoglycemia rate & $\mathrm{I}, 003$ & 1,101 & +98 & 0.637 & 0.664 & +0.028 & 3,550 \\
\hline \multicolumn{8}{|l|}{ Type 2 diabetes } \\
\hline Base case & 627 & 798 & $+|7|$ & 0.520 & 0.640 & +0.120 & $\mathrm{I}, 422$ \\
\hline No BMI disutility & 627 & 798 & $+|7|$ & 0.522 & 0.640 & +0.118 & $\mathrm{I}, 446$ \\
\hline Hypoglycemia rate ratio of $0.7^{39}$ & 593 & 798 & +205 & 0.565 & 0.640 & +0.075 & 2,735 \\
\hline Levy et al hypoglycemia disutility ${ }^{7}$ & 627 & 798 & $+|7|$ & 0.576 & 0.673 & +0.097 & 1,760 \\
\hline Currie et al hypoglycemia disutility ${ }^{10}$ & 627 & 798 & $+|7|$ & 0.562 & 0.665 & +0.103 & $1,66 \mathrm{I}$ \\
\hline Diminishing hypoglycemia utility & 627 & 798 & $+|7|$ & 0.748 & 0.760 & +0.012 & 14,533 \\
\hline Eliasson et al insulin doses ${ }^{33}$ & 594 & 770 & +175 & 0.520 & 0.640 & +0.120 & 1,459 \\
\hline UKHSG base hypoglycemia rate & 432 & 683 & +251 & 0.780 & 0.793 & +0.014 & 18,429 \\
\hline
\end{tabular}

Abbreviations: GBP, 2016 pounds sterling; ICER, incremental cost-effectiveness ratio; QALY, quality-adjusted life year; UKHSG, UK Hypoglycemia Study Group; NPH, neutral protamine Hagedorn; BMI, body mass index.

a relative risk of severe hypoglycemia of $0.665(p<0.001)$ in patients with type 1 diabetes. ${ }^{37}$ While this is a limitation of the analyses presented here, the decision to exclude severe hypoglycemia and improved glycemic control resulted in a highly conservative analysis over a longer time horizon.

In the analyses of both type 1 and type 2 diabetes, reductions in the rate of non-severe hypoglycemia with IDet relative to NPH insulin were derived from a meta-analysis performed by CADTH. ${ }^{22}$ While the meta-analysis reported an overall hypoglycemia rate ratio for IDet relative to NPH insulin of 0.84 (95\% CI 0.74-0.97) in patients with type 1 diabetes, non-severe hypoglycemia was not reported separately and the overall rate was therefore used as a proxy. This was a conservative approach compared with using the rate ratio from the Bartley et al clinical trial (mean rate ratio 0.78 , 95\% CI 0.52-1.16), which was investigated in sensitivity analysis and reduced the ICER to GBP 238 per QALY gained in patients with type 1 diabetes. ${ }^{21}$

In type 2 diabetes, the selected rate ratio of $0.59(95 \%$ CI 0.48-0.72) for non-severe hypoglycemia was based on the CADTH meta-analysis of overall hypoglycemia rates in patients with type 2 diabetes using oral antidiabetic agents in combination with IDet or NPH insulin. ${ }^{22}$ While the metaanalysis finding was significant, the outcome was based on just three randomized controlled trials, which exhibited a high degree of heterogeneity in the reported outcomes $\left(I^{2}=86.9 \%\right.$ based on a chi-squared test outcome of 15.28 over 2 degrees of freedom) ${ }^{22,34,38,39}$ The CADTH analysis authors noted that the heterogeneity may have been driven by the dosing frequency of IDet and NPH, which was not consistent across the three studies. Despite the high degree of heterogeneity, the studies were all directionally in agreement, with mean rate ratios of $0.52,0.54$, and 0.70 for IDet relative to NPH insulin in the Philis-Tsimikas et al, Hermansen et al, and Tajima et al studies, respectively. ${ }^{22,34,38,39} \mathrm{CADTH}$ also noted that the difference was driven by a significant reduction in the frequency but not the risk of overall hypoglycemia, implying that the reductions were a result of reduced rates of hypoglycemia in patients prone to experiencing hypoglycemia rather than a reduction in the proportion of patients having hypoglycemic events. ${ }^{22}$ Such a finding would be congruous with the findings of trials such as HypoAna, which demonstrated significant reductions in hypoglycemia rates in patients prone to recurrent severe hypoglycemia. ${ }^{40}$ Even these reductions may be conservative relative to the differences observed in routine clinical practice, as Phase III regulatory studies of insulin (which need to demonstrate safety) tend to exclude patients who are prone to hypoglycemia.

Sensitivity analyses showed that the results were most sensitive to the use of DMU model to evaluate the effect of hypoglycemia on the quality of life. Such models reduce the incremental disutility associated with each additional hypoglycemic event as overall frequency increases, in this case using a weighted power function to determine the exact 
relationship. ${ }^{36}$ The authors of the DMU model noted that the reduced utility for additional events may be reflective of a range of phenomena, including patients learning to cope with hypoglycemia, an unwillingness to trade-off remaining lifetime after a certain point, or simply respondents paying more attention to the health-state descriptions than the event frequencies. The question of minimally important differences (MIDs) in quality of life should also be considered with regard to the DMU model, as the incremental disutility of additional hypoglycemic events in the model falls below the MIDs for generic instruments such as the Health Utilities Index, EuroQoL-5D (EQ-5D), and 36-Item Short Form Health Survey (SF-36). ${ }^{41,42}$ The DMU model did not capture any reduction in quality of life associated with the fear of hypoglycemia, which has been shown to be greater in patients with experience of hypoglycemia relative to those without, and greater in patients with more severe symptoms of hypoglycemia ${ }^{43}$ The effects of fear may mitigate some of the effects of the DMU model, making the sensitivity analysis highly conservative. Regardless of its conservatism, the analyses in both type 1 and type 2 diabetes still yielded ICERs lower than GBP 20,000 per QALY gained.

Considerable evidence has been published supporting the long-term cost-effectiveness of IDet versus NPH insulin. ${ }^{4-46}$ Whilst these more complex modeling studies are valuable in the absence of long-term clinical trial data, they do not address the requirements of health care payers for whom short-term cost-effectiveness is more relevant to immediate budget considerations. The present study addresses this need by presenting a transparent, short-term analysis of the costeffectiveness of IDet versus NPH insulin based on up-to-date cost data in the UK setting.

\section{Conclusion}

This short-term health economic evaluation showed IDet to be a cost-effective alternative to NPH insulin in both type 1 and type 2 diabetes in the UK. This evaluation reflects the clinically relevant reported reductions in non-severe hypoglycemic episodes, particularly at night, in people with diabetes. In light of the challenging new National Institute for Health and Care Excellence HbA1c targets it may be worth starting longer acting insulin analogues as first line, not only in people with type 1 diabetes but also when initiating insulin therapy in type 2 diabetes patients.

\section{Acknowledgment}

This study was supported by funding from Novo Nordisk Limited.

\section{Disclosure}

Richard F Pollock and William J Valentine are full-time employees of Ossian Health Economics and Communications $\mathrm{GmbH}$, which received consultancy fees from Novo Nordisk Ltd. to develop the model, conduct the analysis, and prepare the manuscript. Barrie Chubb is a full-time employee of Novo Nordisk Ltd., a subsidiary of Novo Nordisk A/S, the marketing authorization holder for IDet. Simon Heller received research grants from Medtronic UK Ltd, has served on speaker panels for Sanofi Aventis, Eli Lilly, Takeda, Novo Nordisk, and Astra Zeneca for which he has received remuneration, and has served on advisory panels or as a consultant for Boehringer Ingelheim, Novo Nordisk, Eli Lilly and Company, and Takeda for which his institution received remuneration. The authors report no other conflicts of interest in this work.

\section{References}

1. The Diabetes Control and Complications Trial Research Group. The relationship of glycemic exposure (HbAlc) to the risk of development and progression of retinopathy in the diabetes control and complications trial. Diabetes. 1995;44(8):968-983.

2. UK Prospective Diabetes Study (UKPDS) Group. Intensive bloodglucose control with sulphonylureas or insulin compared with conventional treatment and risk of complications in patients with type 2 diabetes (UKPDS 33). Lancet. 1998;352(9131):837-853.

3. Stratton IM, Adler AI, Neil HA, et al. Association of glycaemia with macrovascular and microvascular complications of type 2 diabetes (UKPDS 35): prospective observational study. BMJ. 2000;321(7258):405-412.

4. The Diabetes Control and Complications Trial Research Group. Hypoglycemia in the diabetes control and complications trial. Diabetes. 1997;46(2):271-286.

5. Frier BM, Jensen MM, Chubb BD. Hypoglycaemia in adults with insulin-treated diabetes in the UK: self-reported frequency and effects. Diabet Med. 2016;33(8):1125-1132.

6. UK Hypoglycaemia Study Group. Risk of hypoglycaemia in types 1 and 2 diabetes: effects of treatment modalities and their duration. Diabetologia. 2007;50(6):1140-1147.

7. Levy AR, Christensen TL, Johnson JA. Utility values for symptomatic non-severe hypoglycaemia elicited from persons with and without diabetes in Canada and the United Kingdom. Health Qual Life Outcomes. 2008;6:73.

8. Marrett E, Stargardt T, Mavros P, Alexander CM. Patient-reported outcomes in a survey of patients treated with oral antihyperglycaemic medications: associations with hypoglycaemia and weight gain. Diabetes Obes Metab. 2009;11(12):1138-1144.

9. National Institute for Health and Clinical Excellence. Technology appraisal guidance - No. 53. Guidance on the use of long-acting insulin analogues for the treatment of diabetes - insulin glargine. 2002. Available from: http://www.nice.org.uk/TA053. Accessed September 9, 2014.

10. Currie CJ, Morgan CL, Poole CD, Sharplin P, Lammert M, McEwan P. Multivariate models of health-related utility and the fear of hypoglycaemia in people with diabetes. Curr Med Res Opin. 2006;22(8):1523-1534.

11. Davis RE, Morrissey M, Peters JR, et al. Impact of hypoglycaemia on quality of life and productivity in type 1 and type 2 diabetes. Curr Med Res Opin. 2005;21(9):1477-1483.

12. Lundkvist J, Berne C, Bolinder B, Jonsson L. The economic and quality of life impact of hypoglycemia. Eur J Health Econ. 2005;6(3):197-202.

13. Nordfeldt S, Ludvigsson J. Fear and other diturbances of severe hypoglycemia in children and adolescents with type 1 diabetes mellitus. J Pediatr Endocrinol Metab. 2005;18(1):83-91. 
14. Matza LS, Boye KS, Yurgin N, et al. Utilities and disutilities for type 2 diabetes treatment-related attributes. Qual Life Res. 2007;16(7):1251-1265.

15. Hermansen K, Madsbad S, Perrild H, et al. Comparison of the soluble basal insulin analog IDet with NPH insulin: a randomized open crossover trial in type 1 diabetic subjects on basal-bolus therapy. Diabetes Care. 2001;24:296-301.

16. Vague P, Selam JL, Skeie S, et al. IDet is associated with more predictable glycemic control and reduced risk of hypoglycemia than NPH insulin in patients with type 1 diabetes on a basal-bolus regimen with premeal insulin aspart. Diabetes Care. 2003;26:590-596.

17. Kølendorf K, Ross GP, Pavlic-Renar I, et al. IDet lowers the risk of hypoglycaemia and provides more consistent plasma glucose levels compared with NPH insulin in Type 1 diabetes. Diabet Med. 2006;23(7):729-735.

18. Home P, Bartley P, Russell-Jones D, et al. IDet offers improved glycemic control compared with NPH insulin in people with type 1 diabetes: a randomized clinical trial. Diabetes Care. 2004;27(5): 1081-1087.

19. Robertson KJ, Schoenle EM, Gucev Z, et al. Benefits of IDet over NPH insulin in children and adolescents with type 1 diabetes: lower and more predictable fasting plasma glucose and lower risk of nocturnal hypoglycemia. Diabet Med. 2005;22(Suppl 2):45.

20. De Leeuw, Vague P, Selam JL, et al. IDet used in basal-bolus therapy in people with type 1 diabetes is associated with a lower risk of nocturnal hypoglycaemia and less weight gain over 12 months in comparison to NPH insulin. Diabetes Obes Metab. 2005;7:73-82.

21. Bartley PC, Bogoev M, Larsen J, Philotheou A. Long-term efficacy and safety of IDet compared to neutral protamine Hagedorn insulin in patients with type 1 diabetes using a treat-to-target basal-bolus regimen with insulin aspart at meals: a 2-year, randomized, controlled trial Diabet Med. 2008;25(4):442-449.

22. Canadian Agency for Drugs and Technologies in Health. Long-acting insulin analogues for the treatment of diabetes mellitus: meta-analyses of clinical outcomes - update of CADTH technology report No. 92 COMPUS Rep. 2008;2(1). Available from: http://www.cadth.ca/media/ compus/reports/compus_Long-Acting-Insulin-Analogs-Report_Clinical-Outcomes.pdf. Accessed March 7, 2018.

23. Gillespie P, O'Shea E, O'Hara MC, Dinneen SF; Irish DAFNE Study Group. Cost effectiveness of group follow-up after structured education for type 1 diabetes: a cluster randomised controlled trial. Trials 2014;15:227.

24. Fajardo Montañana C, Hernández Herrero C, Rivas Fernández M. Less weight gain and hypoglycaemia with once-daily IDet than NPH insulin in intensification of insulin therapy in overweight type 2 diabetes patients: the PREDICTIVE BMI clinical trial. Diabet Med. 2008;25(8):916-923.

25. National Institute for Health and Care Excellence. Type 1 diabetes in adults: diagnosis and Management. Available from: https://www.nice. org.uk/guidance/ng17/resources/type-1-diabetes-in-adults-diagnosisand-management-1837276469701 Accessed July 5, 2016.

26. Farmer A, Wade A, French DP, Goyder E, Kinmonth AL, Neil A. The DiGEM trial protocol - a randomised controlled trial to determine the effect on glycaemic control of different strategies of blood glucose selfmonitoring in people with type 2 diabetes. BMC Fam Pract. 2005;6:25

27. Farmer A, Wade A, Goyder E, et al. Impact of self monitoring of blood glucose in the management of patients with non-insulin treated diabetes: open parallel group randomised trial. BMJ. 2007;335(7611):132.

28. Evans M, Khunti K, Mamdani M, et al. Health-related quality of life associated with daytime and nocturnal hypoglycaemic events: a time trade-off survey in five countries. Health Qual Life Outcomes. 2013;11(1):90.

29. National Institute for Health and Care Excellence. Type 2 diabetes (partially updated by CG87) (CG66) Appendix C. Available from: http:// www.nice.org.uk/guidance/cg66/resources/cg66-type-2-diabetes-fullguideline-appendices2. Accessed September 9, 2014.
30. Bagust A, Beale S. Modelling EuroQol health-related utility values for diabetic complications from CODE-2 data. Health Econ. 2005;14(3):217-230.

31. Lung TW, Hayes AJ, Hayen A, Farmer A, Clarke PM. A meta-analysis of health state valuations for people with diabetes: explaining the variation across methods and implications for economic evaluation. Qual Life Res. 2011;20(10):1669-1678.

32. Chubb B, Tikkanen CK. The cost of non-severe hypoglycaemia in Europe. Value Health. 2015;18(7):A611.

33. Eliasson B, Ekström N, Bruce Wirta S, Odén A, Fard MP, Svensson AM. Metabolic effects of Basal or premixed insulin treatment in 5077 insulin-naïve type 2 diabetes patients: registry-based observational study in clinical practice. Diabetes Ther. 2014;5(1):243-254.

34. Tajima N, Iwamoto Y, Kaku K, Kawamori R, Nishida T, Kobayashi M. Once-daily IDet added to oral antidiabetic drugs results in less weight gain and a trend for reduced hypoglycaemia in comparison to NPH insulin in Japanese patients with type 2 diabetes. Diabetologia. 2006;49(Suppl 1):609.

35. Donnelly LA, Morris AD, Frier BM, et al. Frequency and predictors of hypoglycaemia in type 1 and insulin-treated Type 2 diabetes: a population-based study. Diabet Med. 2005;22(6):749-755.

36. Lauridsen JT, Lønborg J, Gundgaard J, Jensen HH. Diminishing marginal disutility of hypoglycaemic events: results from a time trade-off survey in five countries. Qual Life Res. 2014;23(9):2645-2650.

37. Szypowska A, Golicki D, Groele L, Pańkowska E. Long-acting insulin analogue detemir compared with NPH insulin in type 1 diabetes: a systematic review and meta-analysis. Pol Arch Med Wewn. 2011;121(7-8): 237-246.

38. Philis-Tsimikas A, Charpentier G, Clauson P, Ravn GM, Roberts VL, Thorsteinsson B. Comparison of once-daily IDet with NPH insulin added to a regimen of oral antidiabetic drugs in poorly controlled type 2 diabetes. Clin Ther. 2006;28(10):1569-1581.

39. Hermansen K, Davies M, Derezinski T, Martinez RG, Clauson P, Home P. A 26-week, randomized, parallel, treat-to-target trial comparing IDet with NPH insulin as add-on therapy to oral glucose-lowering drugs in insulin-naive people with type 2 diabetes. Diabetes Care. 2006;29(6):1269-1274.

40. Pedersen-Bjergaard U, Kristensen PL, Beck-Nielsen H, et al. Effect of insulin analogues on risk of severe hypoglycaemia in patients with type 1 diabetes prone to recurrent severe hypoglycaemia (HypoAna trial): a prospective, randomised, open-label, blinded-endpoint crossover trial. Lancet Diabetes Endocrinol. 2014;2(7):553-561.

41. Drummond $M$. Introducing economic and quality of life measurements into clinical studies. Ann Med. 2001;33(5):344-349

42. Walters SJ, Brazier JE. Comparison of the minimally important difference for two health state utility measures: EQ-5D and SF-6D. Qual Life Res. 2005;14(6):1523-1532.

43. Vexiau P, Mavros P, Krishnarajah G, Lyu R, Yin D. Hypoglycaemia in patients with type 2 diabetes treated with a combination of metformin and sulphonylurea therapy in France. Diabetes Obes Metab. 2008;10(Suppl 1):16-24.

44. Gschwend MH, Aagren M, Valentine WJ. Cost-effectiveness of IDet compared with neutral protamine Hagedorn insulin in patients with type 1 diabetes using a basal-bolus regimen in five European countries. $J$ Med Econ. 2009;12(2):114-123.

45. Tunis SL, Minshall ME, Conner C, et al. Cost-effectiveness of IDet compared to NPH insulin for type 1 and type 2 diabetes mellitus in the Canadian payer setting: modeling analysis. Curr Med Res Opin. 2009;25(5):1273-1284.

46. Palmer AJ, Lammert M, Hermansen K. Sundhedsøkonomiske konsekvenser af insulinanaloger til behandling af type 1-diabetes i Danmark [Health economic consequences of insulin analogues in the treatment of type 1 diabetes in Denmark]. Ugeskr Laeger. 2008;170(15):1250-1254. Danish. 
Diabetes, Metabolic Syndrome and Obesity: Targets and Therapy is an international, peer-reviewed open-access journal committed to the rapid publication of the latest laboratory and clinical findings in the fields of diabetes, metabolic syndrome and obesity research. Original research, review, case reports, hypothesis formation, expert opinion and commentaries are all considered for publication. The manuscript management system is completely online and includes a very quick and fair peer-review system, which is all easy to use. Visit http://www.dovepress.com/testimonials.php to read real quotes from published authors.

Submit your manuscript here: https://www.dovepress.com/diabetes-metabolic-syndrome-and-obesity-targets-and-therapy-journal 